\title{
Could Sars-Cov-2 Reactivate Latent Pulmonary Tuberculosis?
}

\author{
${ }^{1}$ Department of emergency, Moulay Ismail Military Hospital, 50000, Meknes, Morocco \\ ${ }^{2}$ Department of pneumology, Moulay Ismail Military Hospital, 50000, Meknes, Morocco \\ ${ }^{3}$ Department of dermatology, Moulay Ismail Military Hospital, 50000, Meknes, Morocco \\ ${ }^{4,5}$ Department of otolaryngology, Moulay Ismail Military Hospital, 50000, Meknes, Morocco \\ ${ }^{\mathrm{a}}$ Faculty of medicine and pharmacy, Sidi Mohamed Ben Abdellah University, 30000, Fes
}

Amine Elmoqaddem ${ }^{1, a}$, Reda Belghoul ${ }^{2, a}$, Jalal Elbenaye ${ }^{3, a}$, Hamza Belatik ${ }^{4, a *}$, Karim Nadour ${ }^{5, a}$

DOI: $10.36348 /$ sjm.2020.v05i12.008

| Received: 29.10 .2020 | Accepted: 10.11 .2020 | Published: 30.12 .2020

*Corresponding Author: Belatik Hamza

\section{Abstract}

Sars-Cov-2 could occur in active tuberculosis patients; with risk of aggravation, could also reveal tuberculosis or infect former tuberculosis patients.

Keywords: tuberculosis; SARS-CoV-2; aggravation.

Copyright (C) 2020 The Author(s): This is an open-access article distributed under the terms of the Creative Commons Attribution 4.0 International License (CC BY-NC 4.0) which permits unrestricted use, distribution, and reproduction in any medium for non-commercial use provided the original author and source are credited.

\section{INTRODUCTION}

Tuberculosis and Covid-19 share many similarities: both are infectious diseases, mainly affecting the lungs with a similar symptomatology, are contagious, fatal and pandemic with a heavy public health burden. Their association seems much underreported than rare [1]. In Morocco; country still endemic for tuberculosis; this coinfection is redoubtable, especially if it is a possible reactivation of a former tuberculosis by Sars-Cov-2.

A 59 years old woman, with past history of treated pulmonary tuberculosis 15 years earlier, taking metformine for a diabetes mellitus, was admitted in emergency department for fever $\left(38,7^{\circ} \mathrm{C}\right)$, nonproductive cough and respiratory difficulty with fatigue for 4 days. On physical examination, she had oxygen saturation with pulse oximeter $(\mathrm{SaO} 2) 91 \%$ in room air and laboratory analysis revealed that, CRP: $112 \mathrm{mg} / \mathrm{L}$, LDH: 350U/L and remarkable lymphopenia (540). CT scan showed ground-glass opacities with predominantly sub pleural distribution (figure 1). SARS- CoV-2 PCR result was positive from nasopharyngeal sample. She was treated for COVID-19 with Hydroxychloroquine, azithromycin and prophylactic dose of enoxaparine. 5 days after, our patient was still presenting cough, respiratory difficulty with episode of hemoptysis. Ddimers were normal. There was no embol in Angioscanner, but CT scan showed cavitary lesions in right upper zone. Tuberculosis geneExpert was found positive. The diagnosis of Sars-Cov-2 and pulmonary tuberculosis coinfection was retained and after completing COVID-19 specific treatment, anti- TB treatment was continued.

Covid19 pandemic poses a public health problem throughout the world and is especially an alarming situation in countries endemic to tuberculosis. The emergence of tuberculosis following the AIDS pandemic raises fears of a possible emergence with sars-cov-2 coinfection. Strangely enough, we have not observed an increase in tuberculosis cases in these countries but it may be underreported.

Sars-Cov-2 could occur in active tuberculosis patients; with risk of aggravation, could also reveal tuberculosis or infect former tuberculosis patients [2, 3]. The latter could see their tuberculosis reactivated, like our patient. This reactivation could be explained by the immune reaction generated by infection with Sars-Cov2. Indeed, An interplay of various interleukins (IL); triggered by inflammatory response to viral infection; affect T-cell Immune response. Moreover, Type-I interferon (IFN); abnormally secreted as antiviral body response; may promote susceptibility to TB infection. This susceptibility is increased by the association with glucose metabolism disorders, a factor which seems to act on the immune response and constitutes one of the main prognostic factors of Covid-19. This factor was also present in our patient as well as in several other patients with a covid-19 tuberculosis coinfection $[4,5]$.

By this case report we sound the alarm about a possible reactivation of former tuberculosis following infection by Sars-Cov-2, especially if this occurs in a field of deregulation of glucose metabolism. 
Practitioners in tuberculosis-endemic countries should be more vigilant and anticipate a possible tuberculosis outbreak, which would be fatal under the conditions of the Covid-19 pandemic.

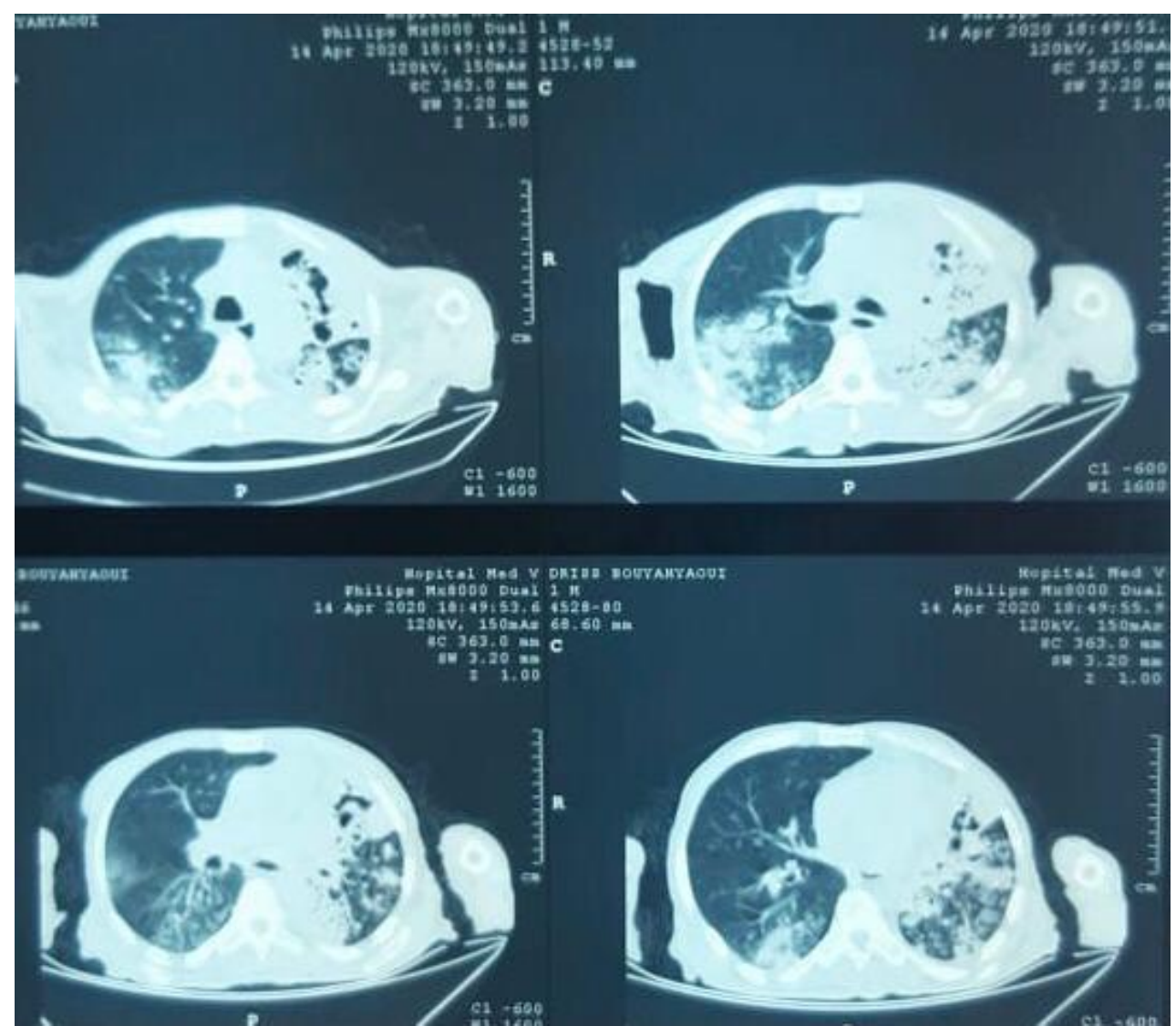

Fig-1: Sequelae of cicatricial fibrosis of former tuberculosis on the left upper lobe, with areas of asymmetric bilateral hyperdensity not systematized in ground glass compatible with covid19

\section{REFERENCES}

1. Bandyopadhyay, A., Palepu, S., Bandyopadhyay, K., \& Handu, S. (2020). COVID-19 and tuberculosis co-infection: a neglected paradigm. Monaldi Archives for Chest Disease, 90(3).

2. Stochino, C., Villa, S., Zucchi, P., Parravicini, P., Gori, A., \& Raviglione, M. C. (2020). Clinical characteristics of COVID-19 and active tuberculosis co-infection in an Italian reference hospital. European Respiratory Journal.

3. Sarınoğlu, R. C., Sili, U., Eryuksel, E., Yildizeli, S. O., Cimsit, C., \& Yagci, A. K. (2020). Tuberculosis and COVID-19: An overlapping situation during pandemic. The Journal of Infection in Developing Countries, 14(07), 721-725.

4. Tadolini, M., Codecasa, L. R., García-García, J. M., Blanc, F. X., Borisov, S., Alffenaar, J. W., ... \& Cardoso-Landivar, J. (2020). Active tuberculosis, sequelae and COVID-19 co-infection: first cohort of 49 cases. European Respiratory Journal.

5. Yousaf, Z., Khan, A. A., Chaudhary, H. A., Mushtaq, K., Parengal, J., Aboukamar, M., ... \& Mohamed, M. F. (2020). Cavitary pulmonary tuberculosis with COVID-19 coinfection. IDCases, 22, e00973. 